\title{
Burnout as a predictor of depression: a cross-sectional study of the sociodemographic and clinical predictors of depression amongst nurses in Cameroon
}

\author{
Clarence Mbanga', Haman Makebe ${ }^{2}$, Divine Tim ${ }^{3,4,5}$, Steve Fonkou ${ }^{6,7}$, Louise Toukam ${ }^{2}$ and Tsi Njim ${ }^{2,4^{*}}$ (D)
}

\begin{abstract}
Background: Depression is a debilitating mental health condition which affects an estimated 350 million people worldwide annually. Nurses are twice as likely to suffer from depression than professionals in other professions. This leads to a considerable loss of efficiency and productivity. We sought to determine the prevalence and predictors of depression among nurses in Cameroon.

Methods: Cross-sectional analysis carried out over 6 months (January - June 2018) using nurses from public and private healthcare institutions sampled consecutively in the two English-speaking regions (North west and South west regions) of Cameroon. The nurses were handed a structured, printed, self-administered questionnaire to fill and hand in at their earliest convenience. Depression and burnout were assessed using the Patient Health Questionnaire -9 and the Oldenburg Burnout Inventory respectively.

Results: A total of 143 nurses were recruited (mean age: $29.75 \pm 6.55$ years; age range: $20-55$ years, 32.87\% male). The overall prevalence of depression was $62.24 \%$. Independent predictors of depression after multivariable analysis were: Number of night shifts a week (adjusted odds ratio: $1.58 ; p$ value: $0.045,95 \% \mathrm{Cl} ; 1.01,2.48$ ) and Total Oldenburg Burnout Inventory score (adjusted odds ratio: 1.21, p value: $0.001 ; 95 \% \mathrm{Cl}$; $1.08,1.35$ ). Recreational drug use was also found to perfectly predict the outcome - depression.

Conclusion: Depression is highly prevalent among nurses in the English-speaking regions of Cameroon. Accurate predictors could prove vital for early detection and management of affected individuals. Predictors presented herein require further investigation via multicentric nationwide studies, to obtain more generalizable results.
\end{abstract}

Keywords: Burnout syndrome, Nurses, Depression, Cameroon, Oldenburg burnout inventory, Patient health Questionnaire-9

\section{Background}

Depression is a major cause of disability worldwide as individuals with this mental health condition usually have low moods, disturbed sleep, negative feelings about life in general and anhedonia; which could lead to decrease efficiency [1-3]. In the United states, it is reported that due to loss of efficiency and productivity in nurses with depression; there

\footnotetext{
* Correspondence: tsinjim@gmail.com

${ }^{2}$ Liverpool School of Tropical Medicine, Pembroke Place, Liverpool L3 5QA, UK

${ }^{4}$ Health and Human (2HD) Research Network, Douala, Cameroon Full list of author information is available at the end of the article
}

is an incurred loss of about 14,339 united states dollars (USD) per nurse; which leads to an estimated national productivity loss of approximately 22.7 billion USD per year [4, 5]. About 350 million people suffer from depression worldwide annually with nurses being twice as likely to suffer from depression than professionals in other fields $[1,3,4]$. Some determinants of depression in nurses are: being married, increased age, longer durations of employment in the nursing profession, a high patient turnover and the presence of burnout syndrome [4]. Other determinants which have been shown to have an association with depression in other populations include: female sex, history of chronic disease,

(c) The Author(s). 2019 Open Access This article is distributed under the terms of the Creative Commons Attribution 4.0 International License (http://creativecommons.org/licenses/by/4.0/), which permits unrestricted use, distribution, and reproduction in any medium, provided you give appropriate credit to the original author(s) and the source, provide a link to the Creative Commons license, and indicate if changes were made. The Creative Commons Public Domain Dedication waiver (http://creativecommons.org/publicdomain/zero/1.0/) applies to the data made available in this article, unless otherwise stated. 
level of studies, occurrence of a major life event (in medical students) [6, 7]; alcohol abuse (in college students) [8]; the presence of problems in social relationships and low income levels in youths and adults $[9,10]$.

Burnout syndrome is a psychological state of emotional exhaustion and disengagement from work due to prolonged exposure to work environment stressors [11, 12]. It is usually described as a reaction to severe stress associated with individuals in "helping professions" [13]. There is a high workload in the health sector in Cameroon, as it is one of the 57 countries described to have a "critical shortage" of healthcare workers [14], with an average health personnel density of 1.3:1000 (below the WHO recommended value of 2.5:1000); and a nurses' density of 0.67 per 1000 [15]. Consequently, there is an increase in patient turnover and a higher workload. As such, nurses in the country are likely to experience burnout syndrome which is possibly a predictor of depression. Some of the symptoms of burnout overlap with those of depression. These overlapping symptoms include extreme exhaustion, depressed moods and reduced performance [13]. As such, there is usually great difficulty in differentiating the two constructs. However, there are symptoms which are specific to burnout syndrome as the negative thoughts an individual may experience are exclusively work-related [13]. An individual with negative ideas about their profession will therefore not necessarily have negative thoughts about life in general.

In this setting where there is usually a lack of mental health service for the general population and for health personnel, we sought to determine the prevalence of depression amongst nurses in the two English-speaking regions of the country and to determine if burnout is a predictor of depression. This study will add to the growing cartography of mental health issues amongst nurses in Cameroon and will raise awareness on the need for the investigation of appropriate preventive measures regarding mental health conditions in the nursing population of Cameroon.

\section{Methods}

\section{Population and design}

This was a cross-sectional analysis carried out over a period of 6 months (January - June 2018) in the two English-speaking regions (North west and South west regions) of Cameroon. The study design was adapted from a series of papers in a project used to assess burnout and depression amongst healthcare personnel and students in Cameroon [7, 16-20]. The predictors of burnout in this population has been published in a previous paper [17]. Ethics approval was obtained from the institutional review board of the Cameroon Baptist Convention. Nurses from public and private healthcare institutions were selected by a consecutive sampling from the
Regional Hospital Bamenda, Regional Hospital Limbe, Regional Hospital Buea, Mutengene Baptist Hospital and Mbingo Baptist Hospital. These hospitals were selected as they were the major functioning hospitals during the ongoing sociopolitical crises in these regions. Nurses working in these institutions at all levels of healthcare (primary, secondary and tertiary) were approached and recruited after a written informed consent was obtained. The nurses were handed a structured and piloted questionnaire to fill and hand in at their earliest convenience. A total of 143 nurses were approached and we received responses from all of them [17].

\section{Study instrument}

Data was collected using a printed self-administered structured questionnaire with three sections.

The first section collected socio-demographic information: age; sex; marital status; hospital of practice (public or private); number of hours spent at work; predominance of shifts (night or day); presence of problems in social relationships; monthly income and the perception of sustainability on monthly income; alcohol use and history of any chronic diseases $[4,8,21]$.

The second section assessed burnout syndrome using the Oldenburg Burnout Inventory (OLBI), which is a self-administered tool consisting of 16 items phrased both in the positive and negative directions. It has two main components which include exhaustion (eight items) and disengagement (eight items). Some of the items included in the exhaustion component were: "During my work, I often feel emotionally drained"; "After working, I have enough energy for my leisure activities"; "After my work, I usually feel worn out and weary"; "Usually, I can manage the amount of my work well" and "When I work, I usually feel energized". Some of the items included in the disengagement component were: "Lately, I tend to think less at work and do my job almost mechanically"; "I find my work to be a positive challenge"; "Over time, one can become disconnected from this type of work"; "Sometimes I feel sickened by my work tasks" and "This is the only type of work that I can imagine myself doing" [11]. The respondents answered the questions according to their perceived frequency of occurrence on a Likert-scale of one to four, ranging from strongly agree to strongly disagree. A participant could therefore have a maximum score of 64 and a minimum score of 4. Previous studies have assessed the use of the OLBI amongst medical and nursing students in Cameroon. These studies showed that the OLBI had a good reliability in these populations with an alpha Cronbach statistic of 0.74 and 0.60 in medical and nursing students respectively $[7,19]$.

The third section assessed depression using the reliable and valid 9-item self-administered Patient Health 
Table 1 Categorical variables showing the sociodemographic characteristics of 143 nurses working in the English-speaking regions of Cameroon assessed for depression from January - June 2018

\begin{tabular}{|c|c|c|c|}
\hline \multirow[t]{2}{*}{ Variable } & & \multicolumn{2}{|c|}{ Total } \\
\hline & & $\mathrm{N}$ & $\%$ \\
\hline \multirow[t]{2}{*}{ Hospital $(n=132)$} & State-owned & 90 & 68.18 \\
\hline & Private sector & 42 & 31.82 \\
\hline \multirow[t]{2}{*}{ Gender $(n=143)$} & Male & 47 & 32.87 \\
\hline & Female & 96 & 67.13 \\
\hline \multirow[t]{2}{*}{ Marital status $(n=142)$} & Single & 73 & 51.41 \\
\hline & Married & 69 & 48.59 \\
\hline \multirow[t]{2}{*}{ Personal relationship $(n=127)^{a}$} & Yes & 78 & 61.42 \\
\hline & No & 49 & 38.58 \\
\hline \multirow[t]{2}{*}{ Difficulties in personal relationship $(n=118)$} & Yes & 26 & 22.03 \\
\hline & No & 92 & 77.97 \\
\hline \multirow[t]{2}{*}{ Majority of shifts $(n=129)$} & Day & 99 & 76.74 \\
\hline & Night & 30 & 23.26 \\
\hline \multirow[t]{2}{*}{ Regret career choice $(n=136)$} & Yes & 23 & 16.91 \\
\hline & No & 113 & 83.09 \\
\hline \multirow[t]{2}{*}{ Occurrence of life changing crises in last 6 months $(n=139)^{b}$} & Yes & 57 & 41.01 \\
\hline & No & 82 & 58.99 \\
\hline \multirow[t]{2}{*}{ Presence of chronic illness $(n=140)^{c}$} & Yes & 17 & 12.14 \\
\hline & No & 123 & 87.86 \\
\hline \multirow[t]{2}{*}{ Alcohol consumption $(n=141)$} & Yes & 71 & 50.35 \\
\hline & No & 70 & 49.65 \\
\hline \multirow[t]{2}{*}{ Recreational drug use $(n=142)^{d}$} & Yes & 7 & 4.93 \\
\hline & No & 135 & 95.07 \\
\hline \multirow[t]{2}{*}{ Sufficient monthly income $(n=133)$} & Yes & 13 & 9.77 \\
\hline & No & 120 & 90.23 \\
\hline
\end{tabular}

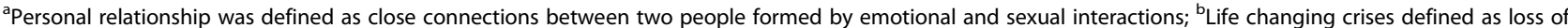
a loved one, physical or sexual trauma and conditions of emotional or social instability ${ }^{\mathrm{C} C h r o n i c}$ illnesses included: Asthma, chronic pelvic pain, diabetes mellitus, gastroesophageal reflux disease, chronic peptic ulcer disease, migraines, cerebral lesions and paralysis; ${ }^{d}$ recreational drugs included: marijuana and tramadol

Table 2 Continuous variables showing the sociodemographic characteristics of 143 nurses working in the English-speaking regions of Cameroon assessed for depression from January - June 2018

\begin{tabular}{|c|c|c|c|c|c|}
\hline \multirow[t]{2}{*}{ Variable } & \multirow[t]{2}{*}{ Number of observations } & \multicolumn{4}{|c|}{ Total sample } \\
\hline & & Mean & SD & Min & Max \\
\hline Age & 108 & 29.75 & 6.55 & 20 & 55 \\
\hline Number of hours at work a week & 127 & 11.50 & 10.80 & 5 & 90 \\
\hline Monthly income in USD & 58 & 125.15 & 75.79 & 0 & 341.59 \\
\hline Number of night shifts a week & 101 & 2.19 & 1.55 & 0 & 8 \\
\hline Quantity of alcohol consumed a week & 41 & 1.83 & 1.33 & 0.5 & 6.5 \\
\hline Total PHQ-9 score & 143 & 6.78 & 4.93 & 0 & 22 \\
\hline Total OLBI score & 143 & 38.36 & 5.68 & 25 & 52 \\
\hline
\end{tabular}

USD United states dollars, GPA Cumulative grade point average, OLBI Oldenburg burnout inventory 
Questionnaire (PHQ-9) [22] which has a sensitivity of $88 \%$ and a specificity of $88 \%$ for the diagnosis of major depression when a PHQ-9 score $\geq 10$ is used [23].

\section{Data management and statistical analysis}

Data entry was done using EPI Info version 7.0 (CDC, Atlanta) software for Microsoft windows. Data entry was double-checked to minimize errors. Data analysis was done using Epi info 7.0 software for Microsoft windows and STATA version 15.0.

A provisional diagnosis of depression was made if the PHQ-9 score was $>4$. The severity of depression was determined using the following classification: mild: 5-9; moderate: $10-14$; moderately severe: $15-19$; and severe: 20-27 [23]. The prevalence of depression amongst participants was calculated in these categories.

The two subscales of the OLBI (emotional exhaustion and disengagement) were used to produce an overall score for burnout syndrome for each participant. These subscales were added up, after reversing the score for negatively phrased questions $(1=4,2=3,3=2,4=1)$. Higher scores therefore indicated higher levels of exhaustion and disengagement, hence burnout.

Univariable analysis was performed using the Fishers exact test with categorical sociodemographic and clinical variables as predictors and depression as the outcome. For continuous variables, the student $t$-test was used. Significance was set at $5 \%$. To determine the independent predictors of depression amongst the nurses, a multivariable analysis was performed where variables which were significant in the univariable analysis were inputted into a logistic regression model. The final variables that were significant in this multivariable logistic regression model were classed as independent predictors of depression.

\section{Results}

\section{Sociodemographic characteristics}

A total of 143 nurses were recruited. The mean age of the participants was $29.75 \pm 6.55$ years (age range; 20-55 years), with 47 (32.87\%) being male. Summaries of the socio-demographic characteristics are shown in Tables 1 and 2 .

\section{Prevalence of depression}

The overall prevalence of depression (PHQ-9 $>4$ ) in the study population was $62.24 \%$ (89/143). Forty-six participants (32.17\%) had mild depression (PHQ-9; 5-9), 32 (22.38\%) had moderate depression (PHQ-9; 10-14), 9 (6.29\%) had moderately severe depression (PHQ-9; 15-19), and 2 (1.40\%) participants had severe depression (PHQ-9; 20-27) (Tables 3). Most of the participants $(60,55.56 \%)$ admitted finding it somewhat difficult in dealing with the symptoms of depression they experienced (Table 4).
Table 3 Categorization of prevalence of depression among 143 nurses working in the English-speaking regions of Cameroon assessed for depression from January - June 2018

\begin{tabular}{lll}
\hline Category of depression & $\mathrm{N}$ & $\%$ \\
\hline None & 54 & 37.76 \\
Mild depression & 46 & 32.17 \\
Moderate depression & 32 & 22.38 \\
Moderately severe depression & 9 & 6.29 \\
Severe depression & 2 & 1.40 \\
Overall depression & 89 & 62.24 \\
\hline
\end{tabular}

\section{Predictors of depression}

Significant predictors of depression on univariable analysis included: number of night shifts a week; total OBLI score; age; and the majority of shifts being night shifts (Tables 5 and 6). Recreational drug use perfectly predicted depression in this population.

After inputting the above listed significant predictors in a multivariable logistic regression model; Number of night shifts a week (aOR;1.58, $p$ value; $0.045,95 \% \mathrm{CI}$; $1.01,2.48)$ and Total OLBI score (aOR;1.21, $\mathrm{p}$ value; $0.001,95 \% \mathrm{CI} ; 1.08,1.35$ ) (Fig. 1) were found to be independent predictors of depression amongst the nurses recruited for the study (Table 7).

\section{Discussion}

Our study aimed at determining the predictors of depression amongst nurses working in both private and public medical institutions in the Englishspeaking regions of Cameroon. Following statistical analysis, independent predictors of depression in our study population were; Number of night shifts per week; the total OLBI score and recreational drug use.

Due to increasing social and economic demands many professionals running night shift systems find difficulties with coping with the associated financial strain. These individuals work mostly during the later hours of the day and at night, resulting in significant disruptions in social and family life [24]. The above considerable strain coupled with the disruption in the normal psychological circadian rhythms associated with night shifts [24] has been shown to have strong associations with mental

Table 4 Difficulties in dealing with depression symptoms among 78 nurses with depression working in the Englishspeaking regions of Cameroon from January - June 2018

\begin{tabular}{lll}
\hline Difficulties in dealing with symptoms of depression & Freq. & Percent \\
\hline Not difficult at all & 34 & 31.48 \\
Somewhat difficult & 60 & 55.56 \\
Very difficult & 9 & 8.33 \\
Extremely difficult & 5 & 4.63 \\
\hline
\end{tabular}


Table 5 Univariable analysis for potential categorical predictors of depression among 143 nurses in the English-speaking regions of Cameroon assessed for depression from January - June 2018

\begin{tabular}{|c|c|c|c|c|c|c|c|}
\hline Variable & Category & Total & $\mathrm{N}$ & $\%$ & OR & $95 \% \mathrm{Cl}$ & $P$ value \\
\hline \multirow[t]{2}{*}{ Gender $(n=143)$} & Male & 47 & 28 & 59.57 & 1.18 & $0.54,2.56$ & 0.646 \\
\hline & Female & 96 & 61 & 63.54 & & & \\
\hline \multirow[t]{2}{*}{ Marital status $(n=142)$} & Single & 73 & 50 & 68.49 & 0.60 & $0.28,1.24$ & 0.140 \\
\hline & Married & 69 & 39 & 56.52 & & & \\
\hline \multirow[t]{2}{*}{ Personal relationship $(n=127)^{a}$} & Yes & 78 & 51 & 65.38 & 1.00 & $0.44,2.26$ & 0.993 \\
\hline & No & 49 & 32 & 65.31 & & & \\
\hline \multirow[t]{2}{*}{ Difficulties in personal relationship $(n=118)$} & Yes & 26 & 19 & 73.08 & 1.75 & $0.62,5.40$ & 0.253 \\
\hline & No & 92 & 56 & 60.87 & & & \\
\hline \multirow[t]{2}{*}{ Monthly income sufficient $(n=133)$} & Yes & 13 & 8 & 61.54 & 0.96 & $0.26,3.97$ & 0.946 \\
\hline & No & 120 & 75 & 62.5 & & & \\
\hline \multirow[t]{2}{*}{ Majority of shifts $(n=129)$} & Night & 30 & 24 & 80.00 & 3.07 & $1.09,9.93$ & 0.021 \\
\hline & Day & 99 & 56 & 56.57 & & & \\
\hline \multirow[t]{2}{*}{ Regret career choice $(n=136)$} & Yes & 23 & 18 & 78.26 & 2.66 & $0.87,9.75$ & 0.063 \\
\hline & No & 113 & 65 & 57.52 & & & \\
\hline \multirow[t]{2}{*}{ Life changing crises $(n=139)^{\mathrm{b}}$} & Yes & 57 & 34 & 59.65 & 0.85 & $0.40,1.81$ & 0.653 \\
\hline & No & 82 & 52 & 63.41 & & & \\
\hline \multirow[t]{2}{*}{ Presence of chronic illness $(n=140)^{c}$} & Yes & 17 & 12 & 70.59 & 1.54 & $0.47,5.91$ & 0.444 \\
\hline & No & 123 & 75 & 60.98 & & & \\
\hline \multirow[t]{2}{*}{ Alcohol consumption $(n=141)$} & Yes & 71 & 46 & 64.79 & 1.23 & $0.59,2.57$ & 0.557 \\
\hline & No & 70 & 42 & 60.00 & & & \\
\hline \multirow[t]{2}{*}{ Recreational drug use $(n=142)^{d}$} & Yes & 7 & 7 & 100.00 & & & 0.034 \\
\hline & No & 135 & 81 & 60.00 & & & \\
\hline \multirow[t]{2}{*}{ Hospital $(n=132)$} & Private & 42 & 27 & 64.29 & 1.20 & $0.53,2.78$ & 0.638 \\
\hline & State-owned & 90 & 54 & 60.00 & & & \\
\hline
\end{tabular}

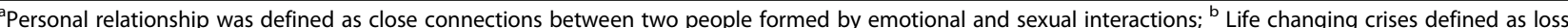
of a loved one, physical or sexual trauma and condition of emotional or social instability ${ }^{\mathrm{C}}$ Chronic illnesses included: Asthma, chronic pelvic pain, diabetes mellitus, gastroesophageal reflux disease, chronic peptic ulcer disease, migraines, cerebral lesions and paralysis; ${ }^{d}$ recreational drugs included: marijuana and tramadol

Table 6 Univariable analysis for potential continuous predictors of depression among 143 nurses working in the English-speaking regions of Cameroon assessed for depression from January - June 2018

\begin{tabular}{|c|c|c|c|c|c|c|c|c|}
\hline \multicolumn{2}{|l|}{ Variable } & \multicolumn{3}{|c|}{ Depression } & \multicolumn{3}{|c|}{ No depression } & \multirow[t]{2}{*}{$P$ value } \\
\hline & Total $(\mathrm{N})$ & $\mathrm{n}$ & Mean & SD & $n$ & Mean & SD & \\
\hline Age & 108 & 66 & 28.35 & 5.16 & 42 & 31.95 & 7.85 & 0.005 \\
\hline Monthly income in USD & 58 & 33 & 125.27 & 71.16 & 25 & 125.00 & 83.00 & 0.989 \\
\hline Number of children & 105 & 62 & 1.77 & 1.56 & 43 & 2.00 & 1.81 & 0.497 \\
\hline Average weekly hours spent at work & 127 & 78 & 10.02 & 4.48 & 49 & 13.86 & 16.29 & 0.051 \\
\hline Number of night shifts a week & 101 & 58 & 2.50 & 1.68 & 43 & 1.77 & 1.25 & 0.018 \\
\hline Total OBLI score & 143 & 89 & 40.11 & 5.42 & 54 & 35.48 & 4.91 & $<0.01$ \\
\hline Quantity of alcohol consumed a week & 41 & 24 & 2.06 & 1.59 & 17 & 1.49 & 0.75 & 0.178 \\
\hline
\end{tabular}




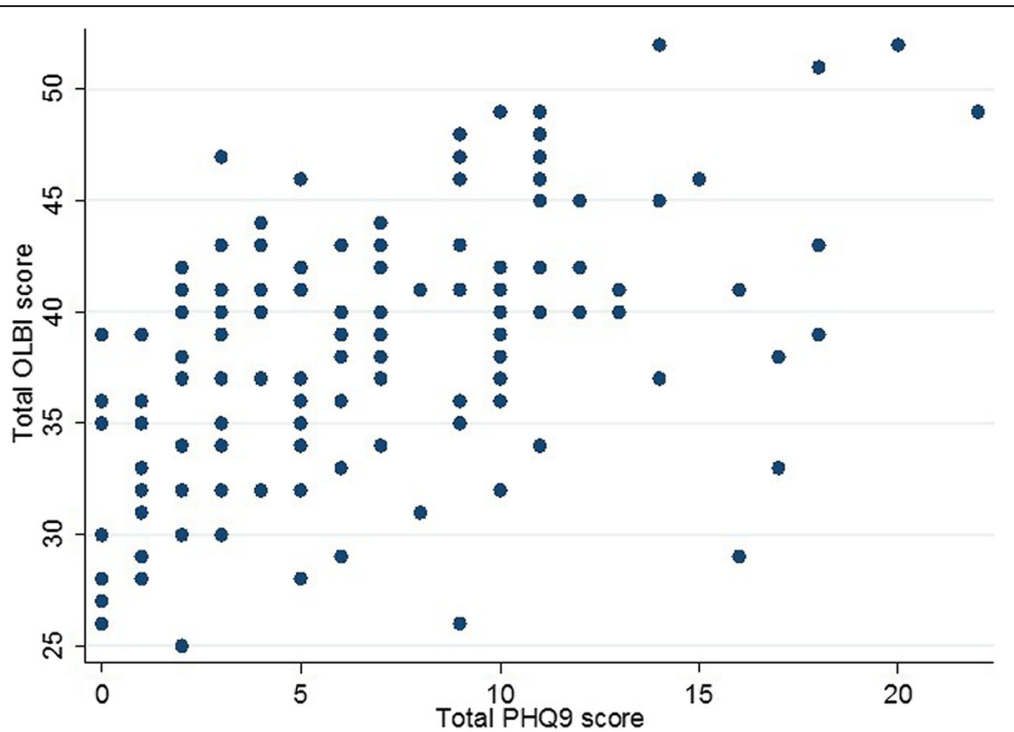

Fig. 1 Scatter plot showing relationship between the total PHQ-9 score on the $y$-axis and the total OLBI score on the $x$-axis

health conditions and symptoms including: insomnia, fatigue and depression [25-28]. The result could be an eventual decrease in staff performance; job satisfaction; exhaustion and eventually burnout [29], which as pointed out by our statistical analysis, is a significant predictor of depression in our study sample.

Adjustment of shift hours so that staffs work shorter night shifts; shift scheduling tailored to the personal problems of individual staff and the allocation of appropriate sleeping hours and sufficient resting days following night shifts, are some of the solutions proposed by authors $[26,29]$. Such solutions are however difficult to implement in a setting like ours where nurses have to work extra hours and shifts, and resume work after just a few days off, in order to fill the void created by the critical shortage of nursing personnel.

The nursing profession could be highly demanding and stressful, be it emotionally or physically. Higher workload, increased turnover, and extended working hours secondary to critical shortage in nursing staff in the country [15], coupled with poor financial remunerations could only go a long way to make the working environment even more stressful and much more difficult to cope with. The end result is a decrease in job satisfaction, gradual exhaustion and disengagement from work and consequently burnout [29]. A lot of debate has however been raised on which of either depression or burnout actually leads to the other, given the overlapping nature of symptoms between the two conditions. The most convincing evidence of burnout leading to depression so far is the study carried out by Hakanen et al on Finish dentist students [30]. The cross-sectional design of our study however meant that we could not establish the direction of this relationship in our sample. This highlights the need for longitudinal studies with greater sample sizes aimed at this purpose.

In this study, recreational drug use was found to perfectly predict the outcome (depression). All seven participants who admitted to using recreational drugs, had depression. Nursing in Cameroon is quite stressful as nurses have to attend to numerous patients a day due to the low nurse-patient density ration in Cameroon. These nurses have to also deal with the emotional pressure of

Table 7 Multivariable logistic regression analysis for independent predictors of depression among 143 nurses working in the English-speaking regions of Cameroon assessed for depression from January - June 2018

\begin{tabular}{llll}
\hline Variables & Adjusted odds ratio & $P$ value & $95 \%$ confidence interval \\
\hline Majority of shifts (Night/Day) & 2.15 & 0.316 & $0.48,9.66$ \\
Age & 0.94 & 0.195 & $0.86,1.03$ \\
Number of night shifts a week & 1.58 & 0.045 & $1.01,2.48$ \\
Total OLBI score & 1.21 & 0.001 & $1.08,1.35$ \\
Recreational drug use $^{a}$ & 1.00 & &
\end{tabular}


looking after critically ill patients daily. This could lead to the use of recreational drugs as an escape mechanism from these pressures.

The management of depression (resulting from working too many night shifts or from burnout syndrome) centers around the need for professional care and support. However mental health is highly neglected in Cameroon as is the case in most African countries [31,32]. Consequently, mental health professionals and mental health institutions are far and wide apart, making it difficult for affected individuals to seek the professional help they need. This highlights the increasing need for the development and deployment of mental health institutions and professionals respectively around the country, in an effort to pay more attention to the mental health of Cameroonians in general, and high-risk individuals such as nurses in particular.

\section{Strengths and limitations}

To the best of our knowledge, this was the first multicenter study to assess the prevalence and potential predictors of depression amongst nurses in Cameroon.

Due to the cross-sectional nature of the study, there is the potential for recall bias in the responses of the participants. Some of the items enquired about practices that are considered societal taboos (recreational drug use for example). This may have affected the way some participants responded to the questions.

Furthermore, the overlapping of symptoms between burnout and depression, coupled to the cross-sectional nature of the study design, made it difficult to assess temporality between the two constructs. Associations obtained should be interpreted with caution.

Findings obtained from our study could hardly be generalizable to the entire nursing population of the country as a whole or the English-speaking regions of the country in particular. This in part due to the convenience nature of our sampling and to the small nature of the sample size. An ongoing socio-political crisis in the two English speaking regions of the country at the time the study was carried out led to the exodus of individuals (nurses inclusive) from the region thereby reducing our sampling pool, and equally made movement to the various recruiting sites challenging.

\section{Conclusion}

Depression is highly prevalent among nurses working in the English-speaking region of Cameroon. Use of accurate predictors could prove vital in the early detection and management of affected individuals especially in high risk professions like nursing. Predictors presented herein however require further investigation via multicentric nationwide studies, to obtain much more generalizable results.

\section{Abbreviations}

OLBI: Oldenburg burnout inventory; PHQ-9: Patient Health Questionnaire-9

\section{Acknowledgements}

None.

\section{Authors' contributions}

Study conception: TN; Literature search: TN, CM; Data collection: CM, HM, DT, SF, LT; Data management: CM; Data analysis: TN; Initial draft of manuscript; CM, TN; Revision of manuscript; CM, TN, HM, DT, SF, LT; Critical revision of manuscript; TN. All authors read and approved the final submitted version of the manuscript.

\section{Funding \\ None.}

\section{Availability of data and materials}

Not applicable.

\section{Ethics approval and consent to participate}

Data was collected only from nurses who had provided written consent to participate in the study. Confidentiality was equally assured by collecting data anonymously. All information obtained during this study was used for the sole purpose of the study. Ethics approval was obtained from the Institutional Review Board of the Cameroon Baptist Convention.

Administrative authorization was obtained from the Regional Delegation of the Ministry of Public Health of the South West region.

\section{Consent for publication}

Not applicable.

\section{Competing interests}

The authors declare that they have no competing interests.

\section{Author details}

${ }^{1}$ Mankon Sub-Divisional Hospital, Bamenda, Cameroon. ${ }^{2}$ Liverpool School of Tropical Medicine, Pembroke Place, Liverpool L3 5QA, UK. ${ }^{3}$ Clinical Research Education Networking and Consultancy, Douala, Cameroon. ${ }^{4}$ Health and Human (2HD) Research Network, Douala, Cameroon. ${ }^{5}$ Baptist Hospital Mutengene, Mutengene, Cameroon. ${ }^{6}$ Faculty of Health Sciences, University of Buea, Buea, Cameroon. ${ }^{7}$ Health Education and Research Organization (HERO), Buea, Cameroon.

Received: 8 October 2018 Accepted: 14 October 2019

Published online: 01 November 2019

\section{References}

1. Moussavi S, Chatterii S, Verdes E, Tandon A, Patel V, Ustun B. Depression, chronic diseases, and decrements in health: results from the world health surveys. Lancet. 2007;370(9590):851-8.

2. Kessler RC, Aguilar-Gaxiola S, Alonso J, Chatterji S, Lee S, Ormel J, et al. The global burden of mental disorders: an update from the WHO world mental health (WMH) surveys. Epidemiol Psichiatr Soc. 2009;18(1):23-33.

3. Marcus M, Yasamy MT, van Ommeren M, Chisholm D, Saxena S. Depression: a global public health concern. Geneva. WHO Department of Mental Health and Substance Abuse. 2012;1(6-8).

4. Brandford AA, Reed DB. Depression in registered nurses: a state of the science. Workplace Health Saf. 2016;64(10):488-511.

5. Letvak SA, Ruhm CJ, Gupta SN. Nurses' presenteeism and its effects on selfreported quality of care and costs. Am J Nurs. 2012;112(2):30-8 quiz 48, 39.

6. Ngasa SN, Sama CB, Dzekem BS, Nforchu KN, Tindong M, Aroke D, et al. Prevalence and factors associated with depression among medical students in Cameroon: a cross-sectional study. BMC Psychiatry. 2017;17(1):216.

7. Njim T, Mbanga CM, Tindong M, Fonkou S, Makebe $H$, Toukam L, et al. Burnout as a correlate of depression among medical students in Cameroon: a cross-sectional study. BMJ Open. 2019;9(5):e027709.

8. Geisner IM, Mallett K, Kilmer JR. An examination of depressive symptoms and drinking patterns in first year college students. Issues Ment Health Nurs. 2012;33(5):280-7. 
9. Teo AR, Choi H, Valenstein M. Social relationships and depression: ten-year follow-up from a nationally representative study. PLoS One. 2013;8(4): e62396.

10. Melchior M, Chastang JF, Walburg V, Arseneault L, Galera C, Fombonne E. Family income and youths' symptoms of depression and anxiety: a longitudinal study of the French GAZEL youth cohort. Depress Anxiety. 2010;27(12):1095-103.

11. Demerouti E, Bakker AB. The Oldenburg Burnout Inventory: A good alternative to measure burnout and engagement. Handbook of Stress and Burnout in Health Care; 2008

12. Maslach C, Schaufeli WB, Leiter MP. Job burnout. Annu Rev Psychol. 2001;52: 397-422.

13. US National Library of Medicine. Depression: What is burnout? : Institute for Quality and Efficiency in Health Care; 2017. Available from: https://www. ncbi.nlm.nih.gov/pubmedhealth/PMH0072470/.Access Date: 13 Feb 2018

14. Global health work force. Health workers for all and all for health workers: The human resource for health crisis. Geneva: World Health Organisation; 2013.

15. Tandi TE, Cho Y, Akam AJ, Afoh CO, Ryu SH, Choi MS, et al. Cameroon public health sector: shortage and inequalities in geographic distribution of health personnel. Int J Equity Health. 2015;14:43.

16. Njim T, Makebe H, Toukam L, Kika B, Fonkou S, Fondungallah J, et al. Burnout syndrome amongst medical students in Cameroon: a crosssectional analysis of the determinants in preclinical and clinical students. Psychiatry J. 2019;2019:4157574.

17. Mbanga C, Makebe H, Tim D, Fonkou S, Toukam L, Njim T. Determinants of burnout syndrome among nurses in Cameroon. BMC Res Notes. 2018;11(1):893.

18. Mbanga CM, Efie DT, Aroke D, Njim T. Prevalence and predictors of recreational drug use among medical and nursing students in Cameroon: a cross sectional analysis. BMC Res Notes. 2018;11(1):515.

19. Njim T, Mbanga C, Mouemba D, Makebe H, Toukam L, Kika B, et al. Determinants of burnout syndrome among nursing students in Cameroon: cross-sectional study. BMC Res Notes. 2018;11(1):450.

20. Feteh VF, Njim T, Nji MAM, Ayeah CM, Sama CB, Tianyi FL. Prevalence and determinants of burnout syndrome among physicians in Cameroon: a research proposal. BMC Res Notes. 2017;10(1):508.

21. Ngasa SN, Sama CB, Dzekem BS, Nforchu KN, Tindong M, Aroke D, et al. Prevalence and factors associated with depression among medical students in Cameroon: a cross-sectional study. BMC Psychiatr. 2017;17(1):216.

22. Kroenke K, Spitzer RL. The PHQ-9: a new depression diagnostic and severity measure. Psychiatr Ann SLACK Inc. 2002;32(9):509-15.

23. Kroenke K, Spitzer RL, Williams JB. The PHQ-9: validity of a brief depression severity measure. J Gen Intern Med. 2001;16(9):606-13.

24. Harrington JM. Health effects of shift work and extended hours of work. Occup Environ Med. 2001;58:68-72.

25. AbuRuz ME, Hayeah HMA. Insomnia induced by night shift work is associated with anxiety, depression, and fatigue, among critical care nurses. Adv Stud Biol. 2017;9(3):137-56.

26. Selvi Y, Özdemir PG, Özdemir O, Aydın A, Beşiroğlu L. Influence of night shift work on Psychologic state and quality of life in health workers. J Psychiatr Neuro Sci. 2010;23:238-43.

27. Ferri P, Guadi M, Marcheselli L, Balduzzi S, Magnani D, Di Lorenzo R. The impact of shift work on the psychological and physical health of nurses in a general hospital: a comparison between rotating night shifts and day shifts. Risk Manage Healthc Policy. 2016;9:203-11.

28. Oyane NM, Pallesen S, Moen BE, Akerstedt T, Bjorvatn B. Associations between night work and anxiety, depression, insomnia, sleepiness and fatigue in a sample of Norwegian nurses. PLoS One. 2013;8(8):e70228.

29. Wisetborisut A, Angkurawaranon C, Jiraporncharoen W, Uaphanthasath R, Wiwatanadate P. Shift work and burnout among health care workers. Occup Med (Lond). 2014;64(4):279-86.

30. Hakanen JJ, Schaufeli WB. Do burnout and work engagement predict depressive symptoms and life satisfaction? A three-wave seven-year prospective study. J Affect Disord. 2012;141(2-3):415-24.

31. Martini S, Arfken CL, Churchill A, Balon R. Burnout comparison among residents in different medical specialties. Acad Psychiatry. 2004;28(3):240-2.

32. Pence BW, Gaynes BN, Atashili J, O'Donnell JK, Tayong G, Kats D, et al. Validity of an interviewer-administered patient health questionnaire-9 to screen for depression in HIV-infected patients in Cameroon. J Affect Disord. 2012;143(1-3):208-13.

\section{Publisher's Note}

Springer Nature remains neutral with regard to jurisdictional claims in published maps and institutional affiliations.
Ready to submit your research? Choose BMC and benefit from:

- fast, convenient online submission

- thorough peer review by experienced researchers in your field

- rapid publication on acceptance

- support for research data, including large and complex data types

- gold Open Access which fosters wider collaboration and increased citations

- maximum visibility for your research: over $100 \mathrm{M}$ website views per year

At BMC, research is always in progress.

Learn more biomedcentral.com/submissions 